\title{
EDITORIAL
}

\section{Do I have a conflict of interest? No}

\author{
Jean-Louis Vincent ${ }^{1 *} \mathbb{D}$, Kenneth B. Christopher ${ }^{2}$ and Anthony McLean ${ }^{3}$
}

๑ 2018 Springer-Verlag GmbH Germany, part of Springer Nature and ESICM

A conflict of interest (COI) can be said to exist when a physician (or his/her company/institution) has an external interest that may appear to alter the way he/ she performs research or practices medicine. Presence of a potential COI can create a perception of diminished investigator independence and thus of decreased research integrity. In recent years, 'definition creep' has occurred with definitions of what constitutes a COI becoming increasingly broad, such that almost any interest can be considered as a potential conflict [1], making COI an unhelpful and meaningless concept [2]. Indeed, it is not unethical to have an interest (most of us do), and moneys gained from industry can help expand research facilities, advance important scientific developments, and support postgraduate education [3]. Moreover, the global playing field is not even and industry support may be the only way doctors from less affluent countries can attend postgraduate courses or become involved in research activities, unlike their counterparts in Europe, Australia or North America where institutional support is more readily available.

COIs can be divided into financial and non-financial conflicts. We believe there is no reason to disclose an intellectual/academic COI, because that is precisely why a person is invited to write an article or review. We will therefore focus on financial COIs, the most frequent form of conflict. Obviously, large financial interests, such as ownership of substantial equity or regular income from a company, must be declared. It is at the other end of the spectrum that the question really arises. Should we declare having had dinner with an industry representative? Or having received a small gift? And then what

\footnotetext{
*Correspondence: jlvincent@intensive.org

1 Department of Intensive Care, Erasme University Hospital, Université libre de Bruxelles, Route De Lennik 808, 1070 Brussels, Belgium

Full author information is available at the end of the article

For contrasting viewpoints, please go to https://doi.org/10.1007/s00134-
} 018-5285-7 and https://doi.org/10.1007/s00134-018-5298-2. qualifies as "small"? And what about an invitation by an industry sponsor to give a presentation - this should clearly be recognized at the start of the presentation, but should agreement to give such a talk constitute a COI in any subsequent publications on the topic? Does a single consultation, or even participation in an advisory group, represent a COI? We do not think so.

Another difficult question is when to declare financial support that has not been provided directly to a person but to his/her institution or organization. Here, also, the real dilemma is not with large amounts of money, but with smaller sums. If a company sponsors a building or gives a large research grant, it is obvious that such a relationship must be declared. Likewise, any industry support for clinical or experimental studies must be acknowledged. But what about sponsorship of scientific meetings? It is very hard, if not impossible, to organize a meeting without industry sponsors. If such grants need to be declared as COIs, all meeting organizers will have a long list, although those who benefit the most from this sponsorship are those who are invited to speak at the meeting. That would mean that all speakers should mention before each talk, and for each publication, all the sponsors of all the meetings to which they are invited!

The easy answer of course is that you declare absolutely everything in a spirit of complete transparency. But, the implications of such an approach are not negligible. Indeed, will you still be seen as independent when you have declared a connection (even a tiny one) with a company involved in the topic? A good example of this problem came during the preparation of the recommendations of the Surviving Sepsis Campaign (SSC) several years ago, when activated protein C (APC) was available [4], and Eli Lilly was naturally promoting the drug. Because there was some concern about a potential influence in the SSC recommendation related to the drug [5], the committee was asked who had not received any support from the company: almost no hands were raised and no "independent" expert on APC could be identified

\section{Springer}


to coordinate the group designated to come up with the recommendation. After long discussions, one person was found to be suitable in terms of no COI, but said it was not his field of expertise and was reluctant to accept. This approach will lead to experts being unable to provide their expertise! Similarly, how can you be consulted for an "independent" opinion by national or international authorities once you have declared even a minor COI? And for how long should received moneys remain potential COIs - 6 months, 1 year, 5 years, forever...? Some experts may refuse to participate in industry-sponsored advisory groups because of the perceived negative connotations of receiving payment and having a COI, yet participation in such discussions could eventually lead to the development of new therapeutic strategies that can help patients. Surely doctors have an intellectual and professional duty to use their expertise to improve patient care.

We support, in general, the principle that authors should declare important COIs before publication. We agree that we need to be transparent about external relationships or activities that could be perceived to influence the way in which we conduct or interpret our research, the tone of our recommendations or the interventions we choose for treating our patients. The problem really is when does a COI pose a threat to the quality of research, the impartiality and honesty of those conducting or reporting it, or the independence of practitioners? The two key words in this debate are 'perceived' -in that receiving industry support can be seen to be an influence even if it does not actually result in loss of objectivityand 'important' -where should the line be drawn between being given a pen and receiving free international air travel to a holiday resort?

We believe that we should set a COI limit; for example, as previously suggested in the New England Journal of Medicine, that stipulated that authors must have no "significant" financial interest in a company and that the 'receipt of honorariums for occasional lectures sponsored by biomedical companies may be appropriately viewed as minor and unlikely to influence an author's judgement' [6]. At the time of that document, an upper limit of around $\$ 10,000$ was set on the annual sum allowed before it became "significant". The $\$ 10,000$ figure was first enacted by regulations published by the US Public Health Service in 1995 [7]. We consider this a reasonable compromise, but these recommendations are not included in the disclosure form from the International Committee of
Medical Journal Editors (ICMJE), which was developed to standardize COI information provided by authors. We believe the question on the form related to what should be declared needs to specify a cut-off amount, below which payments to individuals and/or institutions are not considered as potential COIs.

Transparency is important but should not be exaggerated. Relationships between physicians and industry are often inevitable and can be beneficial; moreover, some conflicts are unavoidable [8]. We need to adopt a rational approach to COIs, accepting that trust between the doctor and patient/reader is paramount, yet more precisely defining acceptable financial and other parameters, and thus putting an end to the increasing and damaging web of vague moral insinuation that is currently happening.

\section{Author details \\ ${ }^{1}$ Department of Intensive Care, Erasme University Hospital, Université libre de Bruxelles, Route De Lennik 808, 1070 Brussels, Belgium. ${ }^{2}$ Division of Renal Medicine, Brigham and Women's Hospital, Harvard Medical School, Boston, Massachusetts, USA. ${ }^{3}$ Department of Intensive Care Medicine, Nepean Hospi- tal, Sydney Medical School, The University of Sydney, Sydney, NSW, Australia.}

\section{Compliance with ethical standards}

Conflicts of interest

Obviously, the authors have no conflicts of interest for this article.

Received: 18 June 2018 Accepted: 2 July 2018

Published online: 20 August 2018

\section{References}

1. Stossel TP (2007) Regulation of financial conflicts of interest in medical practice and medical research: a damaging solution in search of a problem. Perspect Biol Med 50:54-71

2. Kelly $T$ (2016) Conflicts about conflict of interest. Camb Q Healthc Ethics 25:526-535

3. Blumenthal $D$ (1996) Ethics issues in academic-industry relationships in the life sciences: the continuing debate. Acad Med 71:1291-1296

4. Dellinger RP, Levy MM, Carlet JM, Bion J, Parker MM, Jaeschke R, Reinhart K, Angus DC, Brun-Buisson C et al (2008) Surviving Sepsis Campaign: international guidelines for management of severe sepsis and septic shock: 2008. Intensive Care Med 34:17-60

5. Eichacker PQ, Natanson C, Danner RL (2006) Surviving sepsis-practice guidelines, marketing campaigns, and Eli Lilly. N Engl J Med 355:1640-1642

6. Drazen JM, Curfman GD (2002) Financial associations of authors. N Engl J Med 346:1901-1902

7. Public Health Service. Objectivity in Research. Available at: https://grant s.nih.gov/grants/guide/notice-files/not95-179.html.

8. Loewenstein G, Sah S, Cain DM (2012) The unintended consequences of conflict of interest disclosure. JAMA 307:669-670 